\title{
PERCURSO ESCOLAR, PLURALISMO DEMOCRÁTICO E MARCADORES SOCIAIS DA DIFERENÇA: NECESSÁRIAS NEGOCIAÇÕES
}

\author{
Fernando Seffner \\ Doutor em Educação. Professor no Programa de Pós-Graduação em Educação da Universidade \\ Federal do Rio Grande do Sul (UFRGS). Coordenador do Grupo de Estudos de Educação e \\ Relações de Gênero (Geerge). fernandoseffner@gmail.com \\ https://orcid.org/0000-0002-4580-6652 \\ Fernanda Pereira de Moura \\ Mestre em Ensino de História. Professora na Secretaria Municipal de Educação do Rio de Janeiro. \\ Integrante do Movimento Educação Democrática. fernandapmoura@gmail.com \\ https://orcid.org/0000-0001-7194-6870
}

\begin{abstract}
RESUMO
$\mathrm{O}$ artigo se ocupa das conexões entre educação e democracia. Privilegia a escola como território de análise e, nela, professores e professoras, alunos e alunas. Mais do que um regime, a democracia é entendida como forma social e política envolvida na criação e conservação de direitos, e na qual se considera o conflito como algo legítimo e necessário, cabendo ao coletivo construir formas não autoritárias de gestão desse conflito. O pluralismo e a diversidade de ideias e opiniões são elementos produtivos e positivos na educação escolar. Elege-se, então, o terreno dos marcadores sociais da diferença (cor da pele, classe, geração, gênero, sexualidade, religião) como elementos de negociação simultaneamente pedagógica e democrática. Um marcador específico é eleito como fio para análise de situações escolares, marcador esse responsável por grande número de enfrentamentos educacionais contemporâneos - o gênero. Detalham-se os movimentos sociais que hoje, no país, buscam coibir a abordagem dos temas de gênero na educação escolar, a saber, o movimento Escola sem Partido e os ataques produzidos por grupos que se alojam na designação genérica de ideologia de gênero. Pela etnografia de cenas escolares do período da ocupação das escolas públicas no Rio Grande do Sul em 2016, mostramos a produtividade dos debates envolvendo gênero para criação de um ambiente de discussão democrática nas escolas. Compreender que pessoas pensam diferente de nós, que a diversidade é a marca do mundo muito mais do que a homogeneidade, e buscar entender por que elas pensam do modo como pensam, colocando-se na posição do outro, é atitude ligada à busca do conhecimento.
\end{abstract}

Palavras-chave: Educação. Democracia. Marcadores sociais da diferença. Gênero. Escola.

\section{SCHOOL TRAIL, DEMOCRATIC PLURALISM AND SOCIAL MARKERS OF THE DIFFERENCE: NEEDS NEGOTIATIONS}

\begin{abstract}
This paper discusses the connections between education and democracy. It privileges the school as a territory of analysis and, in it, teachers and students. Democracy is understood as a social and political form involved in the creation and conservation of rights. In the democratic regime conflict is considered as something legitimate and necessary, and it is up to the collective to construct nonauthoritarian forms of its management. Pluralism and the diversity of ideas and opinions are productive and positive elements in school education. The social standards of difference (skin color, class, generation, gender, sexuality, religion) are then chosen as elements of pedagogical and democratic negotiation. The social gender standard is chosen as the category of analysis of school situations. We detail the social movements that in the country today seek to curb the approach of gender issues in school education, namely, the movement No Indoctrination and the attacks produced by groups that are based on the designation of gender ideology. By ethnography of school scenes from the period of the occupation of public schools in Rio Grande do Sul in 2016, we show the productivity of debates involving gender to create an environment of democratic discussion in schools. Understanding that people think differently from us, that diversity is the mark of the world
\end{abstract}


much more than homogeneity, and seeking to understand why they think the way they think, putting themselves in the position of the other, is an attitude linked to the pursuit of knowledge.

Keywords: Education. Democracy. Social markers of difference. Gender. School

\section{PERCURSO ESCOLAR, PLURALISMO DEMOCRÁTICO Y MARCADORES SOCIALES DE LA DIFERENCIA: NECESARIAS NEGOCIACIONES}

\section{RESUMEN}

El artículo discute las conexiones entre educación y democracia. Privilegia la escuela como territorio de análisis y, en ella, profesores y alumnos. La democracia es entendida como forma social y política involucrada en la creación y conservación de derecho. En el régimen democrático el conflicto es considerado como algo legítimo y necesario, cabiendo al colectivo construir formas no autoritarias de su gestión. El pluralismo y la diversidad de ideas y opiniones son elementos productivos y positivos en la educación escolar. Se eligen entonces los marcadores sociales de la diferencia (color de la piel, clase, generación, género, sexualidad, religión) como elementos de negociación simultáneamente pedagógica y democrática. El marcador social género es elegido como categoría de análisis de situaciones escolares. Se detallan los movimientos sociales que hoy en el país buscan cohibir el abordaje de los temas de género en la educación escolar, a saber, el movimiento Escuela sin Partido y los ataques producidos por grupos que se alojan en la designación de ideología de género. Por la etnografía de escenas escolares del período de la ocupación de las escuelas públicas en Rio Grande do Sul en 2016, mostramos la productividad de los debates involucrando género para la creación de un ambiente de discusión democrática en las escuelas. Comprender que las personas piensan diferente de nosotros, que la diversidad es la marca del mundo mucho más que la homogeneidad, y buscar entender por qué ellas piensan de la manera en que piensan, poniéndose en la posición del otro, es actitud ligada a la búsqueda del conocimiento.

Palabras clave: Educación. Democracia. Marcadores sociales de la diferencia. Género. Escuela.

\section{DAS NECESSÁRIAS RIMAS ENTRE EDUCAÇÃO E DEMOCRACIA}

Este texto se ocupa de conexões entre educação e democracia. Não de todas as conexões, pois o eixo que liga esses dois conceitos é via larga de muitos fluxos. O artigo toma então, particularmente, a educação escolar como foco de atenção e, para tanto, elege a instituição escola e dois conjuntos de atores sociais como prioritários: professores e professoras, alunos e alunas. Busca saber se as conexões entre educação e democracia são possíveis, desejáveis, existentes. Se estão ameaçadas, ou se são vistas como ameaçadoras, e para quem, nos dois casos. Se estão reguladas em lei, previstas em regimentos escolares, pensadas no ordenamento jurídico. Se são praticadas em sala de aula, e que consequências trazem. Dada a vastidão do tema, que é também a vastidão dos dois conceitos que lhe dão suporte - educação e democracia -, o texto recorta um campo de negociações democráticas na escola, aquelas acionadas pelos marcadores sociais da diferença, a saber: diferenças de gênero, de orientação sexual, de geração, de pertencimento religioso, de classe social, etnia ou cor da pele, de ideário político, de modelo familiar, de origem regional, diferenças 
ligadas à deficiência ou não dos corpos que habitam a sala de aula, dentre outras, pois o universo das diferenças é igualmente vasto. Assumimos que a sala de aula, como muitos espaços sociais, em particular os públicos, é lugar de ampla diversidade. Sentam lado a lado sujeitos que têm diferenças em muitos marcadores. Assumimos que tais diferenças são produtivas para os processos educacionais. Em especial, são boas para o desenvolvimento do raciocínio científico - porque obrigam a esforços de argumentação e convencimento em torno de pontos de vista, ocasionam refinamento na produção de saberes e impedem que as verdades sejam sustentadas pela via do dogmatismo - e são produtivas para o aprendizado de modos de sociabilidade e socialização - já que obrigam a pensar quem somos, quem é o outro, como conviver e desenvolver relações sociais respeitosas em meio a tanta diversidade. O pluralismo que habita a escola - pluralismo de modos de ser, pensar, fazer e viver - é assumido por nós como produtivo e positivo. Não se trata de promover ações pedagógicas para diminuir ou eliminar a diversidade e o pluralismo da escola. Trata-se de trabalhar, do ponto de vista da aquisição do conhecimento científico e da sociabilidade, levando em conta essa riqueza.

Mesmo com os recortes apresentados, o tema segue vasto e impossível de caber em um artigo. Selecionamos, então, um marcador social da diferença específico que provoca, no cenário escolar contemporâneo, fortes debates: gênero. A sala de aula é composta por meninos e meninas, o corpo docente por homens e mulheres. Para além disso, circulam valores sociais e culturais que informam o que é próprio do masculino, o que é próprio do feminino e, sobre esses valores, não há unanimidade de posições, nem na sala de aula, nem na sociedade brasileira como um todo. Abordamos esse tema em dois níveis bem distintos. Por um lado, apresentamos os movimentos sociais que buscam a supressão da abordagem dos temas de gênero na escola, notadamente o Escola sem Partido (ESP), e aquelas iniciativas antigênero que normalmente se abrigam como luta contra a "ideologia de gênero", e mostramos suas estratégias de proposição legislativa. Por outro lado, apresentamos uma etnografia do surgimento do tema de gênero nas ocupações das escolas públicas acontecidas no Rio Grande do Sul, em 2016, por iniciativa de alunos e alunas. Assumimos fortemente que a escola é lugar de diálogo, e que não há diálogo possível quando não há democracia. Anunciamos nossa posição, de certo modo, no título deste tópico, ao escrever "das necessárias rimas entre educação e democracia". Para nós, rimar educação com democracia é um imperativo, embora reconheçamos que há muitos caminhos para que essa rima se efetive, não se trata do "samba de uma nota só". 
Colhemos, então, cenas de sala de aula em que o diálogo sobre os modos de viver e entender as relações de gênero ajudou a ampliar o pensamento sobre a vida na democracia.

Essa é, portanto, a estrutura do artigo. Anunciamos em largas pinceladas algumas de nossas crenças pedagógicas e políticas, e opções de recorte do tema. No tópico seguinte, vamos fazer proliferar sentidos de democracia e educação. Mais adiante, abordamos as diferenças de gênero e aprofundamos a compreensão desse conceito e dos ataques que vem sofrendo, em particular pelo efeito combinado de dois movimentos sociais, conhecidos como ideologia de gênero e ESP. Em outro tópico, apresentamos e analisamos duas cenas escolares em que debates e enfrentamentos de gênero trouxeram a oportunidade de compreender o que é a vida na democracia e ampliar seu sentido. Finalizamos com algumas considerações certamente provisórias, mas que ajudam a indicar caminhos para garantir a produtividade da conexão educação e democracia na prática escolar.

Resta comentar, ainda nesta introdução, o porquê de tratarmos desse tema, nesse contexto histórico específico, nesse país chamado Brasil, ocupando nossa profissão de professor e professora de História, tanto no ensino fundamental como no ensino superior. É possível dizer que voltamos nossa atenção para a democracia como um bem que está principiando a faltar no cenário brasileiro e mundial. Tal como a água que sentimos falta quando a sede aparece, nos demos conta de que uma mistura de descrença na democracia e de cerceamento de seu exercício nos alertaram para a falta que ela faz nos processos educacionais e na vida escolar. Tal tema não é exatamente novo na reflexão política. $O$ mundo já viveu momentos em que a democracia foi percebida como um entrave por grupos que desejavam impor seus modos de pensar. Hannah Arendt (2008, p. 35) nos lembra disso em Homens em tempos sombrios, ao mostrar que há "muito dano por parte daqueles que desejam sujeitar todos os modos de pensar dos homens ao jugo de seu próprio" modo de pensar. É tradição de regimes autoritários, à direita e à esquerda, cercear a democracia, particularmente a democracia na vida escolar e acadêmica.

Enfrentamos então o duplo vetor apontado anteriormente: desprestígio da democracia como forma de governo para organizar a sociedade e ação deliberada de grupos sociais conservadores no sentido de cercear procedimentos democráticos para atender a seus interesses particulares. Esses dois vetores se manifestam na sala de aula, ou pela descrença genérica dos jovens para com a política e a democracia - o que se verifica 
nas pesquisas anuais conduzidas pelo Latinobarómetro Corporación ${ }^{1}$-, ou pela manifestação de alunos e alunas que apoiam com vigor soluções autoritárias para debates e negociações entre diferentes pontos de vista, tratando aqueles que pensam de modo diferente como inimigos a serem calados, no limite, eliminados do debate. Segundo os dados do Informe 2018, do Latinobarómetro Corporación (2018), o Brasil apresenta índices nada alentadores com relação à crença na democracia, e mais de um terço da população não vê diferenças entre viver em um regime democrático ou não democrático. $\mathrm{O}$ Brasil acompanha a tendência latino-americana (e mundial), mostrando que os jovens acreditam menos na democracia do que os velhos:

A medida que disminuye la edad hay mas as indiferencia y autoritarismo. El apoyo al autoritarismo está lejos de ser una cosa de las viejas generaciones. Por el contrario, las nuevas generaciones lo traen de vuelta. El surgimiento de la derecha radical en Europa está también basada en jóvenes de nuevas generaciones, no hay que engañarse que América Latina no es inmune a ese fenómeno. Estamos analizando una muestra de veinte mil casos que tiene significancia estadística del $1 \%$. Es decir, la diferencia de un punto porcentual es significativa. Ello quiere decir que tenemos evidencia dura que el autoritarismo crece a medida que disminuye la edad. Son los más jóvenes los más autoritarios. (LATINOBARÓMETRO CORPORACIÓN, 2018, p. 21-22).

O conjunto de fatores que leva à insatisfação com a democracia no caso brasileiro mais acentuada entre os jovens, como já salientamos - comporta muitos elementos: a sensação de viver em um país dominado pela corrupção e que não consegue fazer frente efetiva a essa prática; uma situação econômica que traz profunda insegurança em relação ao futuro e, principalmente, no tópico empregabilidade; uma desconfiança generalizada nas lideranças políticas, em particular aquelas que por anos já exercem cargos legislativos ou executivos; a descrença nas organizações partidárias como instituições que efetivamente tenham compromisso com demandas de melhoria da população; um vigoroso culto a certo passado autoritário - no caso brasileiro, os anos da ditadura militar de 1964 a 1985 -, em que, de modo idealizado, se diz que não havia corrupção, os maus eram punidos e os cidadãos de bem viviam e trabalhavam em paz; e, por fim, uma persistente sensação de impotência na resolução de problemas pelo uso de estratégias democráticas, o que aumenta a preferência pela eleição de lideranças carismáticas que se apresentam como

\footnotetext{
${ }^{1}$ Referimo-nos às pesquisas anuais sobre o valor da democracia produzidas pelo Latinobarómetro Corporación (2018), uma organização privada sem fins lucrativos, com sede em Santiago do Chile.
} 
"antissistema" e que, à moda de justiceiros ao melhor estilo filmes de Sessão da Tarde, possam restabelecer essa situação ideal mitificada (LAGOS, 2018), com uso combinado da força e da autoridade, e em ambiente de suspensão total ou parcial de direitos e garantias individuais. O nível de escolaridade tem profundo impacto na construção de um sujeito democrático e ajuda a ter esperanças de que as novas gerações, com a melhoria das condições educacionais, são também portadoras do cuidado com a democracia, o que lhes confere uma situação aparentemente paradoxal: ao mesmo tempo, uma parcela desencantada com a democracia e outra comprometida com o cuidado democrático e com a invenção de novos modos de entender o que seja a vida na democracia:

El nivel de educación es determinante en la condición de demócrata, a mayor educación mayor apoyo a la democracia. Es interesante observar que los padres $(15 \%)$ que tienen sólo educación básica, son más autoritários que sus hijos (14\%). [...] Lo que se comprueba en ambas generaciones, la de los hijos y los padres, es que a menor educación mas indiferencia al tipo de régimen. Un 30\% y $31 \%$ (padres e hijos respectivamente) de los que tienen educación básica, les da lo mismo el tipo de régimen. Ese contingente de cerca de 200 millones de votantes en la región es la que esta desarmando el sistema de partidos, eligiendo lideres personalistas, buscando alguien que tenga la varita mágica, quién quiera que sea para "solucionar los problemas". En otras palabras estan rompiendo el establishment. (Latinobarómetro Corporación, 2018, p. 22).

Finalizando essa introdução, vale salientar que duas vertentes de estudos internacionais apontam para certa incógnita na sobrevivência das democracias. A primeira está representada por produções como o já best-seller Como as democracias morrem (LEVITSKY; ZIBLATT, 2018), que nos lembram de que a democracia, como qualquer outra forma histórica, tem certidão de nascimento e pode ter certidão de óbito. Mais ainda, a obra indica que o caminho que leva à morte uma democracia não é exatamente aquele que, no país, já estamos acostumados - golpes militares e movimentos que ficam conhecidos com o nome de revolução, mas que são feitos exatamente para que as revoluções não aconteçam -, podendo ocorrer no dia a dia do exercício de poder de um candidato eleito democraticamente, que vai transformando os opositores em inimigos a serem eliminados - e muitas vezes o são efetivamente, como discutido em Mouffe (2003, 2001, 1999) - ao mesmo tempo em que atropela regras formais e informais da tradição democrática. A outra vertente é conhecida por obras e artigos de Giorgio Agamben (2004), que tratam dessa zona incerta, denominada "estado de exceção", e que vem se 
transformando na regra da organização política atual. Por muitos e diversos motivos ameaça terrorista, chegada de imigrantes em massa, violência e insegurança nas ruas, necessidade de medidas fortes para combater a corrupção, desastres ambientais, enfrentamento de epidemias, possibilidade de guerra iminente, distúrbios e protestos de rua, crise da previdência, crise fiscal, crise econômica, crise, crise, crise, simplesmente crise - somos convencidos de que o exercício do poder está autorizado a tomar medidas de exceção. No caso brasileiro, trata-se do governo por emissão de decretos-lei, da autorização de intervenções militares excepcionais em áreas urbanas, da cobrança de impostos extraordinários, da quebra de direitos já consolidados para fins de ajuste fiscal, da concessão de poderes especiais a juízes, da outorga de poderes incomuns a policiais quando em ação em determinadas áreas da cidade e da suspensão de garantias individuais por motivo de crise. Governar, entre nós, é cada vez mais atividade ligada ao Estado de exceção, à tomada de medidas extraordinárias, a pacotes de reformas, a leis de necessidade. Em conexão com isso, cresce a apreciação da população por governantes que se colocam como mais preparados para o exercício desses poderes discricionários, fazendo pouco caso - quando não ridicularizando abertamente - os procedimentos e instituições democráticas.

É no interior desse complexo quadro de enfrentamentos que buscamos examinar situações escolares, apostando na vitalidade da conexão educação e democracia, mediadas pelas negociações entre diferenças de gênero. Mostramos também como, para os grupos conservadores, a instituição escolar vem sendo objeto de censura, em particular quando aborda temas de gênero.

\section{NA SAla de AUla, A DEMOCRACIA Não PODE ESTAR Só NO CAPÍtUlo DO LIVRO DE HISTÓRIA}

Pensamos a democracia no território escolar como prática e como conteúdo. Não será explicando com métodos autoritários o que é democracia que teremos a boa formação de sujeitos democráticos ao final do percurso escolar. Iniciamos a abordagem pela noção de gestão democrática do ensino. O artigo 206 da Constituição Federal de 1988 (BR ASIL, 1988) aponta os princípios em que se dará o ensino no Brasil. Em seu parágrafo sexto está apresentada a "gestão democrática do ensino público, na forma da lei". Examinando a Constituição Federal encontramos, em diversos momentos, a afirmação de que a 
administração pública deve ter caráter democrático e zelar pela democracia. Mas a única área citada como tendo o dever, definido por lei específica, de ter funcionamento democrático, é aquela do ensino e, dentro dela, a instituição escola. É possível imaginar, a partir do texto constitucional, que a área da saúde e, nela, o hospital público devem funcionar de modo democrático, que uma delegacia de polícia deve atender aos ditames democráticos, que o judiciário deve zelar pela democracia no modo como se organiza, mas é o ensino o único citado como tendo o dever de ser assim, com legislação específica. Ao buscar conexões entre educação e democracia nada mais fazemos do que dar cumprimento à lei. Estabelecida na Constituição, em 1988, a gestão democrática reaparece na Lei de Diretrizes e Bases da Educação Nacional, ali avançando mais alguns contornos:

Art. 14. Os sistemas de ensino definirão as normas da gestão democrática do ensino público na educação básica, de acordo com as suas peculiaridades e conforme os seguintes princípios: I - participação dos profissionais da educação na elaboração do projeto pedagógico da escola; II - participação das comunidades escolar e local em conselhos escolares ou equivalentes. (BRASIL, 1996, art. 14, p. 27.839).

Torna a aparecer na Lei do Plano Nacional de Educação 2014-2024, que indica prazo para estados e municípios atenderem a essa disposição: "Os Estados, o Distrito Federal e os Municípios deverão aprovar leis específicas para os seus sistemas de ensino, disciplinando a gestão democrática da educação pública nos respectivos âmbitos de atuação, no prazo de 2 (dois) anos contado da publicação desta Lei” (BRASIL, 2004). Já tendo transcorrido os dois anos originais para criar leis específicas, levantamento feito indica um panorama incompleto, em que "11 dos 26 estados, além do DF, já possuem normas específicas sobre a matéria, ainda que quase todos os estados apresentem normativas sobre algum dos aspectos concernentes à GD [gestão democrática]" (SOUZA; PIRES, 2018, p. 80). Os mesmos autores indicam clara tendência nas legislações de circunscrever a gestão democrática do ensino à gestão democrática da escola, estratégia importante, mas insuficiente, pois a Constituição Federal fala em democratização do ensino, o que envolve muitos elementos relativos a todo o sistema de ensino e suas relações com outras iniciativas. Tal questão já é de longa data debatida por Saviani (2018), indicando que o esforço em democratizar as relações internas à escola e à sala de aula são condições importantes, mas não suficientes, para formar jovens que tenham afeto pela democracia. Há um delicado trabalho de articulação entre o que se faz e o que se diz no 
território escolar em torno da democracia, e o que se vive e se analisa nos demais ambientes por onde os jovens circulam, como a família, grupos de amigos, clubes, local de trabalho, pertença religiosa, redes sociais, inclusive relações afetivas entre os gêneros essas também pressionadas pelas demandas de equidade de gênero, tópico que escolhemos analisar neste artigo. Também em Saviani (2018) encontramos a discussão que permite pensar a prática pedagógica propriamente dita, marcada por uma situação inicial de diferença etária e de conhecimento, que é um ponto de partida nas relações de ensino e aprendizagem, e de como ela pode ser vivida de forma democrática. De toda forma, proporcionar um funcionamento democrático ao conjunto de atores sociais que vivenciam a escola já é, em país pouco afeito à tradição democrática, uma prática promissora.

Ao acompanhar o cotidiano da vida escolar - seja por visitas de supervisão de estagiários, seja por nele atuar de modo contínuo -, os autores deste texto descreveram em diário de campo muitas ações em sintonia com a gestão democrática, a saber: cartazes informando de modo claro o gasto mensal na escola, indicando a verba recebida e, de modo detalhado, os gastos feitos; assembleias de estudantes para definir regras de funcionamento na escola; consultas por via direta - em assembleias - ou por voto para resolver questões como: detalhes da pintura do muro na frente da escola, sugestões de cardápio da merenda escolar, definições acerca do símbolo da escola, a organização da olimpíada escolar, as atividades da festa junina, o destino da excursão de final de ano e até mesmo a distribuição das turmas de alunos pelas salas. As eleições de liderança de turma, de professor conselheiro de classe, de direção escolar, do grêmio estudantil são, em geral, todas determinadas por métodos democráticos. Na prática de muitas disciplinas, os alunos decidem sobre os modos de elaboração de trabalhos, escolhem entre temáticas diversas aquela que desejam aprofundar os estudos. Em uma escola da grande Porto Alegre, acompanhada durante um ano para observar práticas e modos de viver das culturas ju venis, a decisão sobre o tipo de música que seria tocado no sistema de som na hora do recreio foi objeto de longas consultas, até chegar a uma decisão amplamente debatida e votada pelo conjunto dos alunos de cada turno, envolvendo quais ritmos, em que dias da semana e, mais ainda, quais tipos de música ou letras não seriam tocados, tendo aí uma importante discussão de questões de gênero, particularmente sobre os modos como as mulheres eram referidas nas músicas. Mas foi durante o período de ocupações das escolas públicas, em 2015 e 2016, em diversos estados do Brasil, que práticas democráticas de gestão da vida escolar foram levadas bem adiante, como se verá nas cenas descritas e analisadas adiante. 
Abordamos um conjunto de leis e práticas, mas há muitos modos de estabelecer conexões entre o campo da educação escolar e a democracia. Importa deixar mais claro o que entendemos por democracia. Valemo-nos de autores tanto da ciência política (Chantal Mouffe, Boaventura Sousa Santos, Marilena Chauí, entre outras) como do campo da educação (Paulo Freire, Gert Biesta, entre outros) para apontar os elementos essenciais de nossa compreensão acerca da democracia. Entendemos a democracia como um regime de busca constante de criação de direitos, a partir da identificação de grupos vulneráveis ou em processo de vulnerabilidade, para além de uma ordem legal republicana, preocupada com os valores da liberdade e da igualdade. Mais do que um regime, a democracia é aqui entendida como forma social e política envolvida na criação e conservação de direitos (SANTOS; CHAUÍ, 2013), na qual se considera o conflito como algo legítimo e necessário (MOUFFE, 1999, 2001, 2003), cabendo ao coletivo construir formas não autoritárias de gestão desse conflito. As ações educativas no espaço escolar são simultaneamente pedagógicas e políticas, e trazem a preocupação com a emancipação das condições de vulnerabilidade (FREIRE, 2001), o que guarda estreita relação com a noção de democracia apresentada, preocupada com a ampliação de direitos.

Em particular nos preocupamos com uma educação escolar que auxilie na formação política pessoal para conhecer, conservar e ampliar os direitos. E também em como a trajetória escolar envolve amplos processos de mediação de conflitos, orientados pela noção de modus vivendi (SEFFNER, 2017a) - capacidade de construir acordos entre grupos e pessoas cujas posições divergem, atendendo aos valores do pluralismo democrático e da configuração do espaço público republicano. $\mathrm{O}$ delicado papel do educador nesse processo é destacado por Biesta (2013), que enfatiza a necessidade de valorizar a pluralidade e a diferença, marcas do mundo em que os jovens progressivamente se inserem, sendo a escola instituição central nesse processo, inclusive pelo avanço dos percursos educacionais em todos os países do mundo, seja na duração em número de dias letivos, seja pela via da escola de turno integral, que ocupa os turnos da manhã e da tarde. Assegurar que as crianças escutem sua própria voz, a voz da comunidade de onde provêm e sejam capazes de reconhecer a voz dos demais, se abrindo para a diferença. A escola é ambiente certamente mais plural do que a família e do que a pertença religiosa, por seu caráter público e republicano. Segundo Arendt (2016), é na escola, com mediação de professores e professoras, que a criança é apresentada ao mundo, aprendendo a cuidar dele e por ele se responsabilizando - embora não tenha sido criado por ela, que é nova neste 
mundo, mas que a ele vai dar continuidade. Está envolvido aqui outro delicado equilíbrio, entre passado (tradição) e futuro (invenção), que só pode ser resolvido com plena valência dos ideais democráticos no espaço escolar, evitando tanto a nostalgia - apego demasiado a um passado em geral imaginado - como a perda da memória - invenção de um futuro sem levar em conta o aprendizado das experiências passadas. O que temos, então, é uma educação na e para a democracia. O ambiente democrático colabora para uma educação de qualidade, e esta colabora para um ambiente democrático.

Finalizamos este tópico com o olhar atento para o conjunto de marcadores sociais da diferença que habitam o ensino e a vida na escola. A sala de aula é local de intensa diversidade, própria do espaço público. Conforme já salientamos, sentam lado a lado para conviver, estudar, realizar ações conjuntas, brincar e se divertir ao longo de muitos anos. E, com a escola de turno integral, por muitas horas ao longo do dia, crianças com diferenças de gênero (meninos e meninas); de orientação sexual (meninos que gostam de meninas, meninas que gostam de meninas, meninos que gostam de meninos, dentre outras possibilidades); de pertencimento religioso (não apenas uma multiplicidade de religiões, mas de diferentes modos de a elas se vincular, passando pelos duplos ou triplos pertencimentos e pela pouca atenção ou recusa do sagrado como dimensão importante da vida); de diferentes gerações (mesmo agrupados em sala de aula por idade, o modo de inserção em determinada faixa etária pode variar, e a escola em seu conjunto permite o convívio de crianças e jovens de diferentes idades); de estruturas familiares (casamentos, separações, novos casamentos, filhos do primeiro e do segundo casamento, filhos emprestados, casais do mesmo sexo, mães que cuidam dos filhos com a ajuda de avós, constituindo o agregado reconhecido pelas crianças como família, a presença de animais domésticos como integrantes plenos da família, com direito a nome e posição afetiva, a circulação de crianças que são cuidadas por vizinhas e parentes, mães solteiras, pais solteiros); jovens com inserção em diferentes culturas juvenis (são roqueiros, pagodeiros, meninas que se vinculam a certos artistas e outras a outros, grupos de rap, de funk, adeptos de atividades físicas e da chamada geração saúde ao lado de jovens que não ligam para isso); com diferentes relações com o mundo do trabalho (alguns já trabalham e seu salário é importante no sustento familiar, outros trabalham apenas para satisfazer seus gostos, outros não pensam em trabalhar, alguns já têm definições profissionais, outros não têm ideia do que farão como alternativa profissional); variações quanto à classe social e nível de consumo (vale lembrar que o Brasil está situado há muitas décadas nas estatísticas 
internacionais como exemplo de distribuição muito desigual de renda, e isso se reflete em todo o tecido social e na distribuição de oportunidades e serviços); diferenças em relação à escolaridade dos pais, diferentes disposições corporais (alunos e alunas magros ou obesos, com deficiência física ou mental, considerados bonitos ou bonitas conforme os padrões sociais e culturais); de diferentes etnias e cores de pele (brancos, negros, pardos, indígenas e, cada vez mais, com a presença discreta mas sensível de estrangeiros da América Latina ou de outros continentes); com multiplicidade de opiniões e pertencimentos políticos, desde aqueles e aquelas envolvidos em grêmio estudantil e outras formas de ativismo, até outros e outras que não ligam minimamente para isso; sem contar os que gostam de estudar e ir à escola e aqueles que preferiam dali escapar; dentre outras marcas de diferença - todas constantemente acionadas e negociadas, seja na hora de dar apelidos, de fazer deboches, de se distinguir dos demais, de obter vantagens.

Os embates em torno desses marcadores sociais da diferença ocorrem no terreno já traçado que envolve educação, escola e democracia. Para fins deste artigo, escolhemos focar no marcador gênero, causador de certo pânico social no cenário escolar contemporâneo, pela dupla tensão entre o desejo das culturas juvenis em conversar sobre o tema e as restrições impostas pelos grupos conservadores a sua abordagem (SEFFNER; PICCHETTI, 2016). Buscamos, mesmo que de modo pouco intenso, adotar uma perspectiva que busca ser interseccional. Então, pensamos o marcador gênero em diálogo com outros, modificando e sendo modificado por sexualidade, geração, etnia, pertencimento religioso, classe, nível de escolaridade, disposição corporal etc.

\section{GÊNERO EM PROCESSOS EDUCACIONAIS ESCOLARES: DISPUTAS E TENSÕES}

O marcador social gênero e sua abordagem na escola se tornaram questões essenciais da política brasileira hoje. Tanto o movimento ESP quanto o movimento antigênero do fundamentalismo religioso cristão no Brasil se uniram a ponto de tornaremse praticamente indistintos, e essa união construiu a ideia de que a discussão de gênero é uma forma de ideologia de esquerda que visa destruir a família para, assim, implantar o comunismo. A seguir, caracterizamos esses dois movimentos, mostrando sua origem, princípios, valores e conexões entre eles, bem como suas ações recentes. 
O movimento ESP foi criado em 2004, pelo advogado Miguel Nagib, procurador do estado de São Paulo atuando em Brasília. No mito de fundação do ESP, Nagib é apenas um pai extremamente preocupado com a "doutrinação" que sua filha sofrera na escola no ano anterior, quando seu professor de História teria supostamente comparado a trajetória de Che Guevara à de São Francisco de Assis. Já na história real, Nagib era membro do Instituto Liberal de Brasília e articulista do Instituto Millenium (PENNA; SALLES, 2017). Em um dos artigos que escreveu para esse instituto (SILVA, 2016), deixava claro que seu interesse não era combater a suposta "doutrinação" nas escolas, mas defender a difusão da ideologia neoliberal na educação brasileira. Entretanto, naquele momento, logo após a primeira eleição do Partido dos Trabalhadores (PT) para a Presidência, em que o Brasil vivia uma onda de otimismo com significativa melhoria das condições de vida, não havia espaço entre a população para a difusão do combate à “doutrinação esquerdista" e o movimento permaneceu no ostracismo, apesar de dois grandes veículos de mídia terem tentado alçá-lo à posição de um movimento que merecia ser seguido. Uma reportagem de capa da revista Veja e o editorial do jornalista Ali Kamel em $O$ Globo foram responsáveis pelos únicos quinze minutos de fama que o Escola sem Partido encontrou naquele período, de 2004 a 2010.

Em 2011, no entanto, os grupos conservadores encontraram algo que dialogava muito mais com a maior parte da população brasileira do que a suposta doutrinação comunista: o material de combate à homofobia rotulado por esses grupos de "kit gay" (MOURA; SALLES, 2018). O principal responsável por espalhar versões fantasiosas sobre o material foi o então deputado Jair Bolsonaro. A partir daí a ideia de que a esquerda tenta transformar os estudantes em gays e lésbicas dentro das escolas tem sido difundida na sociedade, principalmente em missas e cultos. O combate à chamada ideologia de gênero termo que surgiu dentro da Igreja Católica (JUNQUEIRA, 2017) - foi absorvido pelas igrejas evangélicas e se tornou a principal razão de existir da bancada da Bíblia no Congresso Nacional. É importante ter em mente que a maioria dos propositores de projetos de leis do ESP são ligados ao fundamentalismo religioso (MOURA, 2016). O discurso da ideologia de gênero vem sendo utilizado em mobilizações da direita em todo o mundo.

Rogério Junqueira (2017) faz uma genealogia do termo começando pelas antifeministas. O autor explica que, em 1994, Christina Hoff Sommers, professora de filosofia de uma universidade americana, em seu livro Who stole feminism? How women have betrayed women, faz uma crítica ao por ela chamado gender feminism, que faria 
mulheres antagonizarem os homens. Em 1997, Dale O’Leary, jornalista norte-americana ligada à Opus Dei e representante do lobby católico em seu livro The gender agenda: redefining equality, defende que o objetivo do feminismo contemporâneo seria criar um mundo com menos pessoas, mais prazer sexual, sem diferença entre homens e mulheres e sem mães em tempo integral. O que, para a autora, seria algo negativo. O padre belga Monsenhor Michel Schooyans publicou, em 1998, seu livro O evangelho face à desordem mundial, com prefácio do cardeal Joseph Ratzinger, que se tornara papa Bento XVI (JUNQUEIRA, 2017). Esse foi, provavelmente, o primeiro livro a utilizar o termo "ideologia de gênero", apresentada como uma ideologia da morte e uma cultura antifamília. No mesmo ano, na Conferência Episcopal Peruana, é lançado o documento $L a$ ideologia de género: sus peligros y alcances, produzido pelo ultraconservador monsenhor Oscar Alzamora Revoredo, bispo auxiliar de Lima. Segundo Junqueira (2017), essa foi a primeira vez que o termo "ideologia de gênero" apareceu em um documento eclesiástico. Dois anos depois, o termo surgiria pela primeira vez em um documento da Cúria Romana na publicação Família, matrimônio e "uniões de fato" do, Conselho Pontifício para a Família (2000).

Como é fácil perceber, o espantalho da ideologia de gênero não é algo recente, assim como também não o é o movimento ESP, mas é a partir do encontro de ambos sendo mobilizados para desestabilizar o governo Dilma que passam a ter notoriedade. De acordo com as argumentações de Luís Felipe Miguel (2016), a oposição que movem religiosos conservadores às questões de gênero não depende do ESP, movimento que iniciou com outra agenda, mas depois se vinculou com os ataques a gênero. Ainda segundo o autor,

[...] o crescimento da importância do MESP no debate público ocorre quando seu projeto conflui para o de outra vertente da agenda conservadora: o combate à chamada "ideologia de gênero". Antes, a ideia de uma "Escola Sem Partido" focava sobretudo no temor da "doutrinação marxista", algo que estava presente desde o período da ditadura militar. O receio da discussão sobre os papéis de gênero cresceu com iniciativas para o combate à homofobia e ao sexismo nas escolas e foi encampado como bandeira prioritária pelos grupos religiosos conservadores. Ao fundi-lo à sua pauta original, o MESP transferiu a discussão para um terreno aparentemente "moral" (em contraposição a "político") e passou a enquadrá-la nos termos de uma disputa entre escolarização e autoridade da família sobre as crianças. (MIGUEL, 2016, p. 596).

O espantalho da ideologia de gênero foi novamente mobilizado em 2014, no processo de votação do novo Plano Nacional de Educação. Nesse momento, utilizou-se 
para desviar a atenção da população de questões essenciais: o próprio combate às desigualdades de gênero; o percentual do PIB destinado à educação; e a possibilidade do repasse de verbas públicas para a educação privada. No mesmo ano, o deputado estadual Flávio Bolsonaro (RJ) encomendou a Nagib um projeto de lei (PL) de censura aos professores, que sugeriu batizar de Programa Escola Sem Partido. O deputado foi, então, o primeiro político a apresentar um PL do ESP em uma casa legislativa, o que foi imediatamente copiado por seu irmão, Carlos Bolsonaro, na Câmara Municipal do Rio de Janeiro. Fica também evidente a profunda ligação do ESP com a família Bolsonaro.

Assim, em 2015, foram protocolados dois projetos de lei fundamentais para entendermos esse movimento de censura. Primero, o Programa Escola Sem Partido (BRASIL, 2015a), proposto pelo deputado federal Izalci Lucas. A proposição seguia basicamente o anteprojeto criado por Nagib a pedido da família Bolsonaro. O texto de oito páginas obrigaria a afixação nas salas de aula e nas salas dos professores das escolas um cartaz "com 70 centímetros de altura por 50 centímetros de largura, e fonte com tamanho compatível com as dimensões adotadas", que supostamente divulgariam a "liberdade de aprender" dos alunos. No discurso do movimento, no entanto, essa liberdade de aprender seria incompatível com a liberdade de ensinar dos professores. Mas não seria incompatível com o suposto direito dos pais de que seus filhos aprendam na escola só o que eles acharem conveniente.

O projeto evoca e fundamenta no artigo 12 da Convenção Americana sobre Direitos Humanos (Pacto de San José da Costa Rica) ${ }^{2}$, segundo o qual "os pais têm direito a que seus filhos recebam a educação religiosa e moral que esteja de acordo com suas próprias convicções". Segundo o PL, "cabe aos pais decidir o que seus filhos devem aprender em matéria de moral" e "um Estado que se define como laico - e que, portanto, deve ser neutro em relação a todas as religiões - não pode usar o sistema de ensino para promover uma determinada moralidade, já que a moral é em regra inseparável da religião". O que não é mencionado, é que o artigo da convenção citado se refere à liberdade de consciência e de religião, e não à educação. Também não é mencionada a existência do Protocolo Adicional de São Salvador, elaborado justamente para dar conta dos direitos econômicos, sociais e culturais não abordados no documento anterior. Segundo esse documento

\footnotetext{
${ }^{2}$ CONVENÇÃO AMERICANA SOBRE DIREITOS HUMANOS, Assinada na Conferência Especializada Interamericana sobre Direitos Humanos, San José, Costa Rica, em 22 de novembro de 1969, disponível na íntegra no site oficial da Comissão Interamericana de Direitos Humanos em https://www.cidh.oas.org/basicos/portugues/c.convencao_americana.htm Acesso em 10 fev. 2019
} 
"esquecido", em seu artigo 13, que versa sobre o direito à educação, as políticas educacionais dos Estados signatários do protocolo deveriam necessariamente defender os Direitos Humanos. Essa composição dos argumentos jurídicos do projeto pode ser interpretada menos como puramente incidental do que como consequência do caráter moralizante que o movimento ESP e seus derivados passaram a assumir a partir de certo ponto. A preocupação com a moral religiosa em um PL sobre educação pública, e, portanto, não confessional, deixa transparecer os reais objetivos das iniciativas em torno da institucionalização do movimento ESP. Entretanto, o PL nº 867, de 2015, não foi o único nesse sentido apresentado pelo deputado.

Assinado por Izalci e outros catorze deputados ${ }^{3}$, o Projeto de Lei $n^{\circ} 1.859$, de 2015, acrescenta o seguinte parágrafo ao artigo $3^{\circ}$ da Lei de Diretrizes e Bases da Educação: “A educação não desenvolverá políticas de ensino, nem adotará currículo escolar, disciplinas obrigatórias, ou mesmo de forma complementar ou facultativa, que tendam a aplicar a ideologia de gênero, o termo 'gênero' ou 'orientação sexual'” (BRASIL, 2015b). O projeto de dezesseis páginas traz em sua justificativa, de mais de quatorze páginas, alguns argumentos que são repetidos em inúmeros projetos e falas conservadoras sobre gênero. $\mathrm{O}$ PL cita trechos de obras de Karl Marx, Friedrich Engels, Kate Millett, Max Horkheimer, John Money, Michel Foucault, Judith Butler e Shulamith Firestone para provar o "totalitarismo" da "ideologia de gênero".

O texto do PL cita supostos trechos de A ideologia alemã e de A origem da família, da propriedade privada e do Estado, seguidos de longas interpretações. José Derisso (2016) demonstrou que as citações são, na verdade, falsificações. Os textos originais são desconstruídos e reconstruídos no texto do PL a fim de servirem de prova para a tese que se quer defender: a de que existe uma conspiração comunista para a destruição da família, uma vez que, segundo esses grupos, essa destruição seria pré-requisito para o comunismo. O texto do PL explica, então, a longa conspiração para a destruição da família e do Estado por meio do uso da chamada "ideologia de gênero":

O que verdadeiramente está acontecendo é que o conceito de "gênero" está sendo utilizado para promover uma revolução cultural sexual de orientação neomarxista com o objetivo de extinguir da textura social a

\footnotetext{
${ }^{3}$ Alan Rick - Partido Republicano Brasileiro (PRB); Antônio Carlos Mendes Thame - Partido da Social Democracia Brasileira (PSDB); Antônio Imbassahy (PSDB); Bonifácio de Andrada (PSDB); Celso Russomanno (PRB); Eduardo Cury (PSDB); Eros Biondini - Partido Trabalhista Brasileiro (PTB); Evandro Gussi - Partido Verde (PV); Givaldo Carimbão - Partido Republicano da Ordem Social (Pros); João Campos (PSDB); Leonardo Picciani - Movimento Democrático Brasileiro (MDB); Luiz Carlos Hauly (PSDB); Rosangela Gomes (PRB); Stefano Aguiar - Partido Socialista Brasileiro (PSB).
} 
instituição familiar. Na submissão do feminino ao masculino através da família, Marx e Engels enxergaram o protótipo de todos os subsequentes sistemas de poder. Se esta submissão é consequência da biologia, não há nada a que se fazer. Mas se ela é uma construção social, ou um gênero, então, a longo prazo, ela poderá ser modificada até chegar-se a uma completa igualdade onde não haverá mais possibilidade de opressão de gênero, mas também onde não haverá mais famílias, tanto as heterossexuais como demais famílias alternativas. Neste contexto, a educação caberia como uma tarefa exclusiva do Estado, e não existiriam mais traços diferenciais entre o masculino e o feminino. Em um mundo de genuína igualdade, segundo esta concepção, todos teriam que ser educados como bissexuais e a masculinidade e a feminilidade deixariam de ser naturais. (BRASIL, 2015b, p. xx.).

Por fim, o texto explica como essa "revolução cultural sexual de orientação neomarxista" foi tramada pela Organização das Nações Unidas (ONU), pela delegação dos Estados Unidos e pela própria primeira-dama americana, Hillary Clinton, ao recomendarem o uso no termo "gênero" no lugar de "sexo" durante a IV Conferência Mundial sobre a Mulher (Pequim, 1995) ${ }^{4}$ sem responder qual seria a definição de gênero e levando as delegações de outros países a adotar o termo por boa-fé, acreditando que "gênero" seria apenas um sinônimo chique para "sexo".

Enquanto produziam seus ataques contra os professores, grupos conservadores construíram para si a imagem de protetores das crianças e dos jovens diante de seus temíveis professores doutrinadores que supostamente desvirtuavam a juventude com sua defesa do comunismo e sexualização precoce. Essas ideias foram defendidas durante a eleição de 2014 e o processo de impeachment, em 2016, nos quais os parlamentares votaram pela família, por Deus, pelo ESP e contra a ideologia de gênero. Após a deposição da presidente eleita, Dilma Rousseff, o movimento advogou a ideia de que o petismo continuaria operante na máquina pública devido ao suposto aparelhamento conduzido pelo PT (BRASIL, 2015a) - assim, “o MEC” e os professores continuariam petistas e mantendo um plano da esquerda para destruir o capitalismo com o ensino da ideologia de gênero e do famigerado "marxismo cultural". Seria preciso, então, ir atrás desses professores. E, por meio dessa narrativa de cruzada, promovendo pânico moral contra os professores, o movimento ESP cresceu e a família Bolsonaro pavimentou seu caminho rumo à Presidência enquanto defensores da "família brasileira sob ataque".

\footnotetext{
${ }^{4}$ Documento final com as Resoluções da Conferência disponível no site oficial da ONU Mulheres em http://www.onumulheres.org.br/wp-content/uploads/2014/02/declaracao_pequim.pdf Acesso em: 10 fev. 2019
} 
O ESP e a família Bolsonaro se retroalimentam. Em 2016, já com mais de cinquenta PLs de censura espalhados em todo o Brasil, o movimento ESP decidiu começar a influir mais abertamente nas eleições. Em seu site, começou a compartilhar os santinhos de candidatos que assinaram o termo de compromisso com o movimento se comprometendo a propor ou a tocar os PLs do ESP já apresentados em suas respectivas casas legislativas quando eleitos. Dentre os candidatos estavam, obviamente, membros da família Bolsonaro, representantes do Movimento Brasil Livre (MBL) e muitos fundamentalistas religiosos. Tendo elegido seus representantes, o movimento ESP pôde se espalhar ainda mais por todo o país. No dia 15 de agosto de 2017, o MBL puxou um dia nacional de mobilização pelo ESP que gerou frutos não no dia, mas nas semanas seguintes. Dessa forma, o ano de 2017 terminou com mais que o dobro de PLs que começou.

Nas eleições de 2018, com mais de 150 projetos ESP em todo Brasil e a crença de que há doutrinação de esquerda acontecendo nas unidades escolares, difundida na sociedade, o movimento ESP voltou a atuar abertamente. Novamente, muitos dos seus candidatos indicados foram eleitos. Uma delas foi a procuradora aposentada Bia Kicis, cunhada de Miguel Nagib, eleita deputada federal. Kicis era uma das líderes do movimento Revoltados Online, ao lado de Marcelo Cristiano Reis e Alexandre Frota. Este último também eleito como deputado estadual em São Paulo. Importante lembrar que, logo após o golpe, esses três foram o primeiro grupo a ser recebido pelo novo ministro da Educação, Mendonça Filho. Segundo eles próprios afirmaram, o ESP havia sido um dos pontos da pauta.

Também foi eleita pela máquina do ESP a agora deputada Ana Caroline Campagnolo, do Partido Social Liberal (PSL) de Santa Catarina, professora de história na educação básica, famosa por ter perdido o processo que moveu contra sua ex-orientadora de mestrado (a professora Marlene de Fáveri, da Universidade do Estado de Santa Catarina), após ter sido reprovada. A aluna se julgou injustiçada por não ter podido defender sua ideia de que ideologia de gênero existe no ambiente acadêmico. Assim como ela, vários outros parlamentares foram eleitos pela indicação do movimento ESP para diferentes cargos em diferentes estados, mas aqui nos interessa particularmente o posicionamento do movimento quanto à Presidência da República. Apesar de três dos candidatos à Presidência defenderem a existência do ESP como lei - Bolsonaro, Henrique Meirelles e Cabo Daciolo, este último tendo, inclusive, apresentado um PL do tipo na Câmara logo antes de se licenciar para concorrer às eleições -, um candidato fora 
escolhido pelo movimento para receber suas bênçãos como sendo o legítimo representante de suas ideias: Jair Bolsonaro, agora eleito presidente. Assim, o ESP e o combate à chamada ideologia de gênero passam a ser políticas de governo.

Com o fim da legislatura no Congresso Federal, todos os projetos de lei de censura que tramitavam foram arquivados, como previsto no regulamento da casa. Isso, no entanto, não significou o fim dos PLs do ESP no nível federal. No primeiro dia da nova legislatura, a já mencionada e agora deputada Bia Kicis (PSL/DF) protocolou o PL Escola Sem Partido $2.0 \mathrm{n}^{\mathrm{o}} 246 / 2019^{5}$, ao qual voltaremos no final deste artigo. O traçado histórico que realizamos permite perceber a centralidade, no debate político atual, das questões de gênero em sua conexão tanto com o território escolar quanto com a pauta da democracia e do respeito ao pluralismo e à diversidade. No próximo tópico vamos examinar duas situações dentro do território escolar em que questões de gênero e condução democrática entram em cena pelas mãos dos jovens.

\section{UM OLHAR SOBRE A ESCOLA: DEMOCRACIA DE GENERO NAS OCUPAÇÕES}

Em maio de 2016, inicia-se no Rio Grande do Sul um ciclo de ocupações de escolas públicas estaduais, que durará cerca de dois meses, envolvendo um número ainda impreciso de escolas, mas em torno de 250, situadas na capital, região metropolitana e cidades de médio e grande porte pelo interior do estado. Imediatamente estabelecemos uma rotina de acompanhamento do movimento, conforme apresentado em Seffner (2017b). A narrativa abaixo, extraída do diário de campo e com reflexões nela inseridas posteriormente, acompanha principalmente o movimento em duas escolas: a) uma de grande porte, de ensino médio e próxima à região central da cidade, agregando alunos de muitos bairros diferentes, e com grande tradição de ativismo estudantil; b) e outra de menor porte, de ensino fundamental e ensino médio, situada em bairro distante do centro e região marcadamente popular, agregando alunos de bairros bem próximos, com pequena tradição de ativismo estudantil. Nos dois casos foi possível acompanhar situações envolvendo disputas de gênero e com importante interface com a democracia. Começamos pelo relato comentado da escola de menor porte. Nome da escola e dos alunos e alunas

\footnotetext{
5 Disponível para consulta íntegra na em: <https://www.camara.leg.br/proposicoesWeb/fichadetramitacao?idProposicao=2190752>. Acesso em: 22 fev. 2019.
} 
envolvidos foram omitidos por questões de ética. O tom narrativo do diário de campo foi preservado. As cenas foram acompanhadas e descritas pelo primeiro autor deste artigo.

Já estou bastante conhecido dos alunos e alunas da escola X. Alguns, inclusive, me conhecem das constantes visitas de supervisão de estágio, por ser uma escola preferida pelos estagiários que oriento todo semestre. Fico impressionado com a forte presença de alunos e alunas na ocupação, com cerca de quarenta dormindo todas as noites e o dobro disso participando das atividades ao longo do dia. Mais ainda, me impressiono com a arrecadação de gênero alimentícios, feita toda em minimercados da região e casas de família. Já por três vezes os encarregados da cozinha me mostraram com orgulho as geladeiras e o freezer da cozinha cheios, e salientaram que fizeram doação para outra escola, do município ao lado, que não tinha tanta comida. A ocupação é coordenada por uma menina e um menino, e sua representação no comitê das escolas ocupadas se faz também por uma menina e um menino. Tal composição não é casual, as meninas me disseram que isso tudo foi discutido, pois logo no início tinha ficado acertado que as gurias cuidavam da ocupação na escola e os guris participavam das reuniões e articulações junto às demais escolas, reproduzindo certa divisão entre o espaço doméstico e o espaço público. Posteriormente, algumas meninas me disseram que, na verdade, no início nem tinha havido discussão, simplesmente "aconteceu assim", como me disse uma delas. Os guris começaram a ir às reuniões nas escolas centrais - iam de bicicleta - e as gurias ficavam cuidando da escola, o que significava limpar, arrumar, cozinhar, entre outras coisas. Dois dias depois do início da ocupação esse tema foi discutido e a distribuição modificada. Papel importante nisso tiveram os grupos de WhatsApp organizados, que permitiram às alunas dessa escola perceber que, em outras escolas, fazia-se uma divisão igualitária entre meninos e meninas em todos os postos.

A partir daí, tive ocasião de assistir a duas reuniões de planejamento das atividades e a composição das comissões para o trabalho do dia, anotando em grandes cartazes de papel pardo os nomes. Na primeira dessas reuniões assistidas foi possível perceber que a divisão de gênero foi levada de maneira matemática, aí incluídas ocupações consideradas um tanto perigosas, como o turno de guarda da madrugada, horário em que todos tinham medo que a brigada militar ou os movimentos de desocupação tentariam entrar na escola fato que efetivamente aconteceu em outras escolas, embora sempre sem sucesso. Nesse horário, após breve discussão, também os postos foram preenchidos por uma menina e um menino. Conversei depois com a menina que ficaria no posto de guarda da madrugada, 
perguntando se ela não tinha medo. Respondeu de imediato que sim, tinha medo, mas que a divisão deveria ser feita assim mesmo, e que alguma menina tinha que ficar ali ao lado do menino. Retornei à escola três dias depois, chegando lá às $7 \mathrm{~h} 15 \mathrm{~min}$ com algumas coisas para o café coletivo, sempre na tentativa de observar o modo como estavam se organizando para dormir e quem preparava o café da manhã, ao qual se seguia a assembleia. A manhã estava muito fria e bastante ensolarada. Os colchões, travesseiros, lençóis e cobertores foram trazidos para a quadra de esportes e colocados para tomar sol. Alunos e alunas ali se abancaram com as canecas de café e pão, e a assembleia iniciou. Solicitei licença para permanecer e assistir, que me foi concedida, mas sem direito de fala nem de voto, repetindo um padrão que já havia vivido em outras escolas. Um grupo de meninas, a certa altura, comunicou que no dia anterior elas haviam se reunido e criado um coletivo feminista na escola, e que o grupo ainda não tinha nome - estavam convidando outras meninas para a primeira reunião geral. Tal iniciativa eu já havia visto em outras escolas, num movimento registrado posteriormente em vídeos e com notas na imprensa e matérias mais longas da Mídia Ninja ${ }^{6}$. Alguns meninos, entre bem-humorados e ligeiramente debochados, comentaram que era "clube do Bolinha". Um deles disse: "começaram os feminismos", e uma das meninas respondeu que sim, eram os feminismos contra o machismo. Houve burburinhos, ficou marcada a reunião do coletivo apenas com meninas para depois do almoço, e o assunto ficou por isso. Ao final da assembleia um grupo de meninos veio até mim, sentou ao redor, indo direto ao assunto - sabiam que eu pesquisava masculinidades e queriam sugestões para também formar um coletivo. Cabe explicar que, na semana anterior, em atividade conjunta de quatro escolas dessa região acontecida em outra escola, eu estive presente, e um dos meus orientandos deu uma oficina sobre gênero e sexualidade para um grupo de meninos e meninas. Essa oficina foi bastante concorrida, embora tenha acontecido em paralelo com outras oficinas. Então, eles já me conheciam.

Foi muito interessante perceber que os meninos queriam organizar o coletivo claramente para ter organização similar à das meninas, mas não tinham ideia de temas, que nome dariam, o que poderia haver de assuntos comuns a eles. Também não tinham domínio do vocabulário envolvido nas questões de gênero, diferentemente das meninas, que utilizam expressões como feminismo, falam em Frida Kahlo, usam a palavra gênero,

\footnotetext{
${ }^{6} \mathrm{O}$ documentário mais completo sobre o protagonismo feminino nas ocupações chama-se Lute como uma menina, dirigido por Flávio Colombini e Beatriz Alonso, disponível em: <https://www.youtube.com/watch?v=80CUMGHm2oA >. Acesso em: 22 fev. 2018.
} 
falam em opressão feminina, da mulher na história e têm propostas de igualdade. Mas eles tinham claro que, como tudo estava se fazendo de modo igualitário e democrático entre meninos e meninas - distribuição das tarefas, estruturação das comissões, organização do dormitório, contagem dos tempos de fala nas assembleias - a iniciativa das meninas tinha que ser respondida por algo semelhante do lado de cá. É conveniente lembrar que as ocupações das escolas no Rio Grande do Sul tinham pauta de luta e reivindicação que não contemplava nenhuma questão específica de gênero, estava composta pela oposição ao projeto ESP que tramitava na assembleia legislativa, listava carências da escola que deveriam ser supridas, falava em melhoria da qualidade da educação, pedia maior voz dos alunos e alunas nas decisões, era contra a parceria público-privada na gestão escolar e apoiava o movimento dos professores e professoras na luta salarial. A equidade de gênero foi o modo como eles viveram a ocupação - os dias e noites passados juntos na escola -, não constituiu uma pauta externa, mas uma decisão de organização interna.

$\mathrm{Na}$ escola de ensino médio a situação que estabelecia conexão entre democracia e gênero era de outra ordem. No início do ano letivo as eleições para o grêmio estudantil, disputadas por três chapas, haviam dado vitória a uma chapa composta exclusivamente por meninas que ficou conhecida como "o grêmio das meninas". Com a ocupação, o grêmio estudantil assumiu a coordenação das ações na escola, o que cumpre lembrar, não foi a regra. Em muitas outras escolas as ocupações foram coordenadas por comissões criadas para esse fim e, em algumas delas, o grêmio estudantil foi literalmente destituído ou ficou sem ação alguma. Outro fato é que alguns grêmios estudantis eram compostos por grupos identificados com partidos políticos, então, os ocupantes decidiram que não havia como serem representados por eles, pois as ocupações foram movimentos bastante avessos às questões político-partidárias.

Assisti a diversas assembleias gerais nessa escola, a bem dizer, parte de assembleias, pois eram muito longas, com pautas muito extensas. As meninas do grêmio estudantil coordenavam as assembleias, embora tivessem instalado divisão paritária em todas as comissões: limpeza, segurança, comunicação, recepção, cozinha, portaria, saúde e lazer. Em uma das assembleias algumas meninas, não integrantes do grêmio estudantil, levantaram a questão de que em outras escolas a coordenação da ocupação era feita por grupos mistos de meninos e meninas, e talvez se devesse fazer isso ali também. Enfatizo aqui: foram meninas que levantaram a questão. A maioria dos meninos presentes concordou de imediato. As três meninas do grêmio estudantil que no momento 
coordenavam a assembleia não aceitaram a proposição, dizendo da sua representatividade, que ia além da ocupação e envolvia os demais alunos, pois tinham ganhado a eleição com votos dos três turnos da escola. Novamente entrou o conceito de democracia, com alunos e alunas dizendo que democracia era ter meninos e meninas de modo igualitário em todas as ações da ocupação, o que incluía a coordenação. E as meninas do grêmio dizendo que sua escolha tinha sido feita em outro momento, para representar os alunos, em eleições livres, com um número muito maior de alunos e alunas votantes. Não pude ficar até o final do debate. Alguns dias depois, retornando à escola, informei-me a respeito conversando com diversos alunos e alunas. A decisão final tinha sido de permanecer o grêmio estudantil coordenando a ocupação. Uma menina com quem conversei foi enfática, dizendo que na maior parte dos mais de cem anos de idade da escola o grêmio estudantil tinha sido composto só por meninos, ou com poucas meninas. E que agora, que havia uma chapa apenas de meninas, elas tinham o direito de seguir coordenando. Levei esse argumento para conversar com um grupo de meninos, que disse concordar em parte, pois a chapa não havia sido eleita para tratar da ocupação, ninguém sabia que a escola seria ocupada. Mas reconheceram que as meninas coordenavam muito bem e que a imprensa estava sempre na escola para filmar, em grande parte, porque eram meninas que coordenavam a ocupação.

Gostaríamos de tecer dois breves comentários acerca do relato da etnografia dessa segunda escola por conterem questões para as quais não temos respostas prontas, mas que parece urgente refletir. Primeiro, nos chamou atenção que, mesmo com um grêmio de meninas eleito democraticamente, reconhecido pelo bom trabalho e que estava participando ativamente da organização da ocupação, tenha sido cogitado e defendido que esse grêmio não deveria ser o responsável pela organização da ocupação, já que em outras escolas a representação de gêneros estaria sendo paritária. Nos perguntamos se, tendo as ocupações começado em maio de 2016 - mesmo momento da abertura do processo de impeachment e consequente afastamento da então presidenta Dilma Rousseff -, a ideia de que as representantes eleitas para o grêmio poderiam ter sua posição de liderança política contestada com tamanha facilidade não teria algo a ver com o "espírito do tempo". Outra coisa que nos parece um elemento importante para reflexão é o porquê da crença de que substituir o "grêmio de meninas" por uma representação paritária de gênero seria mais democrático.

Nas eleições presidenciais de 2018, vimos três candidatos à Presidência trazerem mulheres como suas vices: Fernando Haddad, com Manuela D’Ávila; Ciro Gomes, com 
Kátia Abreu; e Guilherme Boulos trouxe Sônia Guajajara. Esta última, inclusive, não era chamada por seu companheiro de vice, e sim de cocandidata. Se homens puderam por tanto tempo governar sozinhos, por que mulheres não poderiam? Por que a representação paritária seria capaz de atribuir mais legitimidade democrática que uma eleição ocorrida dentro dos ditames da democracia representativa? Não temos respostas, mas julgamos que essas perguntas precisavam ser enunciadas para que pudéssemos todos, autores e leitores, juntos buscar por respostas.

\section{PARA SEGUIR PENSANDO}

Compreender que pessoas pensam diferente de nós, que a diversidade é a marca do mundo muito mais do que a homogeneidade, e buscar entender por que elas pensam do modo como pensam, colocando-se na posição do outro, é atitude ligada à busca do conhecimento. É, então, a atitude a ser privilegiada no trabalho escolar. Não se trata apenas de aceitar o outro - seu jeito de ser, suas ideias e opiniões, seus valores políticos - por uma razão moral, ao estilo "vou aceitar o colega que é gay, coitado, ele é assim, mas vou aceitar". Perceber a diversidade do mundo e com ela se relacionar de modo positivo é dinâmica cognitiva. Buscar uma escola que garanta a diversidade e o pluralismo democrático é atitude de abertura científica e que promove uma sociabilidade cidadã. São esses os valores que se encontram sob ameaça.

Assim, voltamos ao já mencionado PL n ${ }^{\circ} 246$ de 2019, da deputada Bia Kicis ${ }^{7}$, apresentado como Escola Sem Partido 2.0. Mantendo a mesma estrutura do PL ESP anterior, essa nova versão corrige as inconstitucionalidades mais evidentes do projeto anterior ao mesmo tempo em que recrudesce a perseguição a professores e, agora, também a alunos. Tal como o anterior, o projeto recorre ao artigo 12 da Convenção Americana de Direitos Humanos (CADH) para tentar se legitimar juridicamente. Em seu artigo $2^{\circ}$, declara que "o Poder Público não se imiscuirá no processo de amadurecimento sexual dos alunos nem permitirá qualquer forma de dogmatismo ou proselitismo na abordagem das questões de gênero" e, em seu artigo $3^{\circ}$, que "é vedado o uso de técnicas de manipulação psicológica destinadas a obter a adesão dos alunos a determinada causa". No artigo $7^{\circ}$, assegura aos estudantes o direito de gravar as aulas de seus professores com a desculpa de

\footnotetext{
7 Disponível na íntegra e com os registros de tramitação em https://www.camara.leg.br/proposicoesWeb/fichadetramitacao?idProposicao=2190752 Acesso em: 20 fev. 2019
} 
"permitir a melhor absorção do conteúdo ministrado e de viabilizar o pleno exercício do direito dos pais ou responsáveis de ter ciência do processo pedagógico e avaliar a qualidade dos serviços prestados pela escola" e, no artigo $8^{\circ}$, veda aos grêmios estudantis a promoção de atividade considerada político-partidária. Pessoas de boa-fé poderiam ser levadas a acreditar que apenas a organização partidária seria um problema, mas sabemos que, quando se trata de denunciar uma posição política contrária o movimento ESP, trata todas as manifestações políticas como sinônimos de partidárias. A seguir, em seu artigo 11, declara que o "Poder Público" (sem declarar qual poder público seria) “contará com canal de comunicação destinado ao recebimento de reclamações relacionadas ao descumprimento desta Lei, assegurado o anonimato". Por fim, traz em parágrafo único que as reclamações "deverão ser encaminhadas ao órgão do Ministério Público incumbido da defesa dos direitos da criança e do adolescente, sob pena de responsabilidade". Na justificativa do PL declaram que

É fato notório que professores e autores de livros didáticos vêm se utilizando de suas aulas e de suas obras para tentar obter a adesão dos estudantes a determinadas correntes políticas e ideológicas, bem como para fazer com que eles adotem padrões de julgamento e de conduta moral - especialmente moral sexual - incompatíveis com os que lhes são ensinados por seus pais ou responsáveis.

Fica claro o quanto gênero e sexualidade são temas essenciais para esse movimento, assim como fica evidente a contradição sobre quem são os alunos para o movimento ESP. Enquanto no artigo 8 vedaram a organização política dos grêmios estudantis, na justificativa, declaram que tem o professor "o dever de não se aproveitar da audiência cativa desses alunos, para promover suas próprias preferências religiosas, morais, ideológicas, políticas e partidárias”. Afinal, os estudantes são audiência cativa ou sujeitos políticos que podem ser organizar a fim de exigir seus direitos? Caso os estudantes sejam os responsáveis pela realização de discussões de gênero tais como ocorreram nas ocupações e, caso eles voltem a ocupar as escolas, poderão ser eles também enquadrados pela lei? Membros de um grêmio serão tratados como menores infratores?

Também é digno de nota que, tal como o projeto ESP anterior (PL n 867/2015) tinha seu projeto-espelho - o PL n ${ }^{\circ}$ 6.005/2016, Escola Livre (BRASIL, 2016), do deputado Jean Wyllys, do Partido Socialismo e Liberdade (PSOL-RJ) -, o atual projeto 
ESP também tem seu projeto-espelho, o PL n ${ }^{\circ} 502 / 2019^{8}$, Escola Sem Mordaça (BRASIL, 2019), apresentado pelas deputadas Talíria Petrone (PSOL-RJ), Luiza Erundina (PSOLSP), Fernanda Melchionna (PSOL-RS), Sâmia Bomfim (PSOL-SP) e Áurea Carolina (PSOL-MG). Novamente pensando no espírito do tempo, parece-nos significativo que a liberdade de aprender e ensinar esteja resguardada por um representante da comunidade LGBTQ $+{ }^{9}$ ou pela representação feminista. Como pudemos observar nos últimos tempos, desde a derrubada do deputado Eduardo Cunha até as grandes manifestações contra o então candidato Bolsonaro, passando pelas anuais marchas do orgulho, são esses movimentos e essas pessoas que estão se mantendo nas ruas na luta pelos seus (nossos) direitos e pela democracia no país. E estão deixando claro que possuem a clareza de que a educação é essencial para a manutenção e expansão da democracia. A tarefa posta, e já em parte em execução por alunos nas ocupações e professores e professoras, é aquela de valorizar e aprofundar as conexões entre democracia e educação, e buscar a democratização da própria democracia, entendendo que o debate dos marcadores sociais da diferença ajuda a construir uma sociedade democrática.

\section{REFERÊNCIAS}

AGAMBEN, G. Estado de exceção: (Homo Sacer, II, I). São Paulo: Boitempo, 2004.

ARENDT, H. Homens em tempos sombrios. São Paulo: Companhia das Letras, 2008.

ARENDT, H. A crise na educação. In: ARENDT, H. Entre o passado e o futuro. São Paulo: Perspectiva, 2016. p. 221-247.

BIESTA, G. Para além da aprendizagem: educação democrática para um futuro humano. Belo Horizonte: Autêntica, 2013.

BRASIL. Constituição da República Federativa do Brasil de 1988. Brasília, DF, 1988. Disponível em: <http://www.planalto.gov.br/ccivil_03/constituicao/constituicaocompilado.htm>. Acesso em: 22 fev. 2018.

BRASIL. Lei $\mathrm{n}^{\circ}$ 9.394, de 20 de dezembro de 1996. Estabelece as diretrizes e bases da educação nacional. Diário Oficial da União, Brasília, DF, 23 dez. 1996. Seção 1. p. 27.839. Disponível em: <http://www.planalto.gov.br/ccivil_03/LEIS/L9394.htm>. Acesso em: 22 fev. 2018.

\footnotetext{
8 Disponível na íntegra e com os registros de tramitação em https://www.camara.leg.br/proposicoesWeb/fichadetramitacao?idProposicao=2191271 Acesso em: 20 fev. 2019

${ }^{9}$ Lésbicas, gays, bissexuais, travestis, transexuais ou transgêneros e queers.
} 
BRASIL. Lei no 13.005, de 25 de junho de 2004. Aprova o Plano Nacional da Educação PNE, e dá outras providências. Brasília, DF, 2004. Disponível em: <http://www.planalto.gov.br/ccivil_03/_Ato2011-2014/2014/Lei/L13005.htm>. Acesso em: 22 fev. 2018.

BRASIL. Câmara dos Deputados. Projeto de Lei $\mathbf{n}^{\mathbf{0}}$ 867/2015. Inclui, entre as diretrizes e bases da educação nacional, o "Programa Escola sem Partido". Brasília, DF, 2015a. Disponível em: <https://www.camara.leg.br/proposicoesWeb/fichadetramitacao?idProposicao=1050668>. Acesso em: 18 out. 2016.

BRASIL. Câmara dos Deputados. Projeto de Lei $\mathbf{n}^{\mathbf{0}}$ 1.859, de 10 de junho de 2015. Acrescenta Parágrafo único ao artigo $3^{\circ}$ da Lei 9.394/96 (Lei de Diretrizes e Bases da Educação). Brasília, DF, 2015b. Disponível em: $<$ https://www.camara.leg.br/proposicoesWeb/fichadetramitacao?idProposicao=1302894>. Acesso em: 18 out. 2016.

BRASIL. Câmara dos Deputados. Projeto de Lei $\mathbf{n}^{\mathbf{0}}$ 6.005, de 16 de agosto de 2016. Institui o programa "Escola livre" em todo o território nacional. Brasília, DF, 2016. Disponível em: <https://www.camara.leg.br/proposicoesWeb/fichadetramitacao?idProposicao=2094685>. Acesso em: 18 out. 2016.

BRASIL. Câmara dos Deputados. Projeto de Lei $\mathbf{n}^{\mathbf{0}}$ 502, de 6 de fevereiro de 2019. Institui o programa "Escola sem Mordaça" em todo o território nacional. Brasília, DF, 2019.

em: <https://www.camara.leg.br/proposicoesWeb/fichadetramitacao?idProposicao=2191271>. Acesso em 9 mar. 2019.

CONSELHO PONTIFÍCIO PARA A FAMÍLIA. Família, matrimônio e "uniões de $<$ http://www.vatican.va/roman_curia/pontifical_councils/family/documents/rc_pc_family_ doc_20001109_de-facto-unions_po.html>. Acesso em: 22 fev. 2018.

DERISSO, J. L. Marxismo e história da família: resposta aos opositores da chamada "ideologia de gênero" na educação. In: SEMINÁRIO NACIONAL DO HISTEDBR - 30 ANOS DO HISTEDBR: CONTRIBUIÇÕES PARA A HISTÓRIA E A HISTORIOGRAFIA DA EDUCAÇÃO BRASILEIRA, 10., 2016, Campinas. Anais... Campinas: Unicamp, 2016. Disponível em: <https://www.fe.unicamp.br/eventos/ged/histedbr2016/xhistedbr/paper/viewFile/1029/196 >. Acesso em: 22 fev. 2018.

FREIRE, P. Política e educação: ensaios. São Paulo: Cortez, 2001.

JUNQUEIRA, R. D. "Ideologia de gênero": a gênese de uma categoria política reacionária - ou: a promoção dos direitos humanos se tornou uma "ameaça à família natural"? In: RIBEIRO, P. R. C.; MAGALHÃES, J. C. (Org.). Debates contemporâneos sobre educação para sexualidade. Rio Grande: Edgraf, 2017. p. 25-52. 
LAGOS, M. El fin de la tercera ola de democracias. Santiago: Corporación Latinobarómetro, 2018. Disponível em: <http://www.latinobarometro.org/lat.jsp>. Acesso em: 22 fev. 2018.

LATINOBARÓMETRO CORPORACIÓN. Informe 2018. Santiago, 2018. Disponível em: <http://www.latinobarometro.org/latNewsShow.jsp>. Acesso em: 22 fev. 2018.

LEVITSKY, S.; ZIBLATT, D. Como as democracias morrem. Rio de Janeiro: Zahar, 2018.

MOUFFE, C. Feminismo, cidadania e política democrática radical. Debate Feminista. São Paulo: Cia. Melhoramentos, 1999. (Edição Especial Cidadania e Feminismo). p. 2947.

MOUFFE, C. Identidade democrática e política pluralista. In.: MENDES, C.; SOARES, L. E. (Org.). Pluralismo cultural, identidade e globalização. Rio de Janeiro: Record, 2001. p. $410-430$.

MOUFFE, C. Democracia, cidadania e a questão do pluralismo. Política \& Sociedade, Florianópolis, n. 3, p. 11-26, out. 2003.

MOURA, F. P. de. "Escola Sem Partido": relações entre Estado, educação e religião e os impactos no ensino de história. 2016. 189 f. Dissertação (Mestrado Profissional em Ensino de História) - Instituto de História, Universidade Federal do Rio de Janeiro, Rio de Janeiro, 2016.

MOURA, F.; SALLES, D. C. O Escola sem Partido e o ódio aos professores que formam crianças (des)viadas. Revista Periódicus, Salvador, v. 1, n. 9, p. 136-160, 2018.

O'LEARY, D. The gender agenda: redefining equality. San Francisco: Vital Issues Press, 1997.

PENNA, F.; SAllES, D. C. A dupla certidão de nascimento do Escola Sem Partido: analisando as referências intelectuais de uma retórica reacionária. In: MUNIZ, A. C.; LEAL, T. B. (Org.). Arquivos, documentos e ensino de história: desafios contemporâneos. Fortaleza: EdUECE, 2017. p. 13-37.

SANTOS, B. S.; CHAUÍ, M. Direitos humanos, democracia e desenvolvimento. São Paulo: Cortez, 2013.

SAVIANI, D. Escola e democracia. Campinas: Autores Associados, 2018.

SEFFNER, F. A escola e a construção de um "modus vivendi" de valorização da diversidade e de respeito aos diferentes modos de ser. In: RIOS, J. A. V. P. (Org.). Diferenças e desigualdades no cotidiano da educação básica. Campinas: Mercado de Letras, 2017a. p. 227-256.

SEFFNER, F. Ocupar é viver a escola. In: CATTANI, A. D. (Org.). Escolas ocupadas. Porto Alegre: CirKula, 2017b. p. 13-40. 
SEFFNER, F.; PICCHETTI, Y. P. A quem tudo quer saber, nada se lhe diz: uma educação sem gênero e sem sexualidade é desejável? Reflexão e Ação, Santa Cruz do Sul, v. 24, p. 61-81, 2016.2 Disponível em: $<$ https://online.unisc.br/seer/index.php/reflex/article/view/6986/pdf >. Acesso em: 22 fev. 2018.

SILVA, R. C. A. A ideologia do Escola sem Partido. Professores contra o Escola sem Partido, [S.1.], 2016. Disponível em: <https://profscontraoesp.org/2016/06/03/a-ideologiado-escola-sem-partido/>. Acesso em: 19 fev. 2019.

SOUZA, A. R.; PIRES, P. A. G. As leis de gestão democrática da educação nos estados brasileiros. Educar em Revista, Curitiba, v. 34, n. 68, p. 65-87, mar./abr. 2018. Disponível em: <http://www.scielo.br/pdf/er/v34n68/0104-4060-er-34-68-65.pdf>. Acesso em: 19 fev. 2019.

Recebido: $05 / 03 / 2019$

Aceito: $30 / 03 / 2019$ 